Proceedings of the Creative Construction Conference (2018)

Edited by: Miroslaw J. Skibniewski \& Miklos Hajdu

DOI 10.3311/CCC2018-077

Creative Construction Conference 2018, CCC 2018, 30 June - 3 July 2018, Ljubljana, Slovenia

\title{
Measuring project risk management performance: a preliminary model
}

\author{
Larissa Rubio $^{\mathrm{a}}$, Alfredo Serpell ${ }^{\mathrm{b}, *}$, Ximena Ferrada $^{\mathrm{c}}$ \\ ${ }^{a}$ Department of Construction Engineering and Management, Pontificia Universidad Católica de Chile, Vicuña Mackenna 4860, Santiago, Chile \\ ${ }^{b}$ Faculty of Civil Engineering, Universidad del Desarrollo, Av. Plaza 680, Santiago, Chile \\ ${ }^{c}$ School of Civil Construction, Pontificia Universidad Católica de Chile, Vicuña Mackenna 4860, Santiago, Chile
}

\begin{abstract}
The function of project risk management (PRM) is to understand the uncertainty that surrounds a project and to identify the potential threats than can affect it as well as to know how to handle these risks in an appropriate way. Then, the measuring of the performance of PRM becomes an important concern, an issue not addressed yet in the research literature. It is necessary to know how successful is the application of the PRM process, and how capable is the process within the organization. Regarding construction projects, it is essential to know if the selected responses to mitigate or eliminate identified risks were suitable and well implemented. This paper presents a critical analysis of the relevance of measuring the performance of PRM and the benefits of doing so. Additionally, it presents a preliminary and pioneering methodology to measure the performance of PRM through the evaluation of the adequacy of the responses applied to mitigate risks, as well as to evaluate the resulting impacts as indicators of the effectiveness of these actions. This knowledge will allow construction companies to incorporate good practices, generate lessons learned, and thereby promote a continuous improvement of the whole PRM process.
\end{abstract}

(C) 2018 The Authors. Published by Diamond Congress Ltd., Budapest University of Technology and Economics Peer-review under responsibility of the scientific committee of the Creative Construction Conference 2018.

Keywords: Performance; measurement; risk management; projects; key performance indicators.

\section{Introduction}

The construction industry faces major challenges in relation to the performance of its projects [1], [2]. Uncertainty accompanies globalization and technological advances, which can become risks in projects. If this situation occurs, these risks could produce impacts with negative consequences in the fulfilment of the objectives of projects, such as the cost, schedule, scope, and quality [3], [4], [5], [6]. For this reason, it is necessary to prevent the occurrence or being prepared with good mitigating responses if they occur, through an adequate management of risks.

However, no studies have been found so far with the focus on how to monitor and control the performance of risk management effectively. PRM is considered an activity of the planning stage of the project and there is a lack of post facto analysis of how it really worked. This paper raises the importance of addressing the issue of measuring the performance of risk management in construction projects, an issue not reported in the literature. It aims to establish a different perspective of risk management focused at the end of a project, and to evaluate what risks occurred, which ones were previously identified, what really happened with the risks that occurred, the impacts produced by them and how effective was the application of risk responses [7], [8].

The paper begins with a review of the literature, addressing the issues of how to evaluate the performance of risk management and why it is important to do this for construction projects. Subsequently, a brief description of the 
research and the model for PRM performance measurement are discussed in a preliminary manner. The paper ends with the conclusions and a brief discussion of following research stages to achieve the final objective of this study.

\section{Literature Review}

\subsection{Performance measurement}

Defined by [9], performance measurement is an instrument that helps to quantify the efficiency or effectiveness of an action, which provides information on what is happening regarding that action. Different organizational areas use performance measurement [10]. The main concern for many organizations is to achieve the strategic objectives defined by them, in addition to measuring the effectiveness of the established processes [11]. In order to achieve this, there are several approaches, such as the PMS (Performance Measurement System). This system defines key performance indicators or KPIs, which allow evaluating and measuring the achievement of objectives, identifying the type of measurements, establishing the mechanisms to obtain the data, describing and analyzing the results, and establishing the necessary actions that shall be made in order to improve [12], [13].

Among the most used tools for measuring performance is the Balanced Score Card, developed by Kaplan \& Norton in 1993. Because of its ease of application and the information it provides, it is widely used among organizations. [14] adapted this tool to measure the performance of enterprise risk management in organizations.

Since organizations set strategic objectives, measuring their performance becomes a fundamental part of defining whether these objectives are being achieved. This is a permanent activity within organizations for closing gaps, identifying opportunities, establishing mechanisms to solve problems, and improving processes continuously. This is particularly important for those processes that are critical for the success of projects [15].

This paper is concerned with measuring the performance of one of these processes, project risk management, considered so important for construction projects. Given its relevance, it is important to understand the behavior of risks to try to handle them in an appropriate way in order to minimize their impact [2].

\subsection{Risk Management}

Given the current uncertainty and the recent global economic crisis of 2008, risk management has gained more importance and has revealed the deficiency of its application at both, organizational, and project level [16], [17]. Organizations such as the Project Management Institute (PMI), the International Organization for Standardization (ISO), and the Australia's Standards Organization as well as academics, professionals, experts, and governments, among others, have expressed their concerns about this issue. As a result, standards for its application, procedures, tools, techniques and some computing programs that support the application of risk management for a better functioning of enterprises and projects have been developed [2]. In general, the main operational concerns of risk management are on the following topics: 1) the identification of risks; 2) risk analysis and evaluation; 3) the development of techniques, tools and software that help with the application of risk management; and 4) the evaluation of the RM maturity within organizations [18], [19].

Several authors have investigated about risk and risk management, raising the interest from different industries and organizations [16], [20], [21], [22]. The risk management process includes five main stages [7], [21], [22], [23], [24], [25], [26], [27], [28], [29], [30], [31], [32], [33]. These stages are: 1) risk management planning; 2) risk identification; 3) risk analysis and evaluation; 4) response plan to risks; and 5) monitoring and control of risks. In addition, these stages can be divided into two main pillars: 1) identification and analysis, that includes the stages of risk management plan, risk identification and risk analysis and evaluation, and 2) responses and control, including the stages of response and monitoring plan and control [16], [34].

[16], [35], [2], note that the greater emphasis of the application of risk management has focused mainly on the risk identification and analysis stages. There is a lack of connection of these stages with the risk response plan and monitoring and control part producing a lack of knowledge about the effectiveness of the strategies to face risks and about the impacts of these strategies on project results.

In the construction industry, risk management is considered a bureaucratic and tedious activity usually applied only at the beginning of the life cycle of the project and merely regarding risk identification and analysis. The nature of projects that this industry carries out are usually characterized by a great deal of uncertainty and many restrictions of various kinds, which makes it necessary to try to identify as exhaustively as possible the risks that may arise and how they might impact the objectives. This activity should be part of the organizational culture permeating at all levels so 
that it can be incorporated into the project management and carried out throughout the life cycle of the project. At the end to evaluate how well the risk management performed, i.e., if responses were effective and what influence they had on project objectives [1], [2], [25].

This was evident in a survey conducted in 2013 by the KPMG, an international financial and taxation consultant based in Holland. It showed within its main results that risk management in the construction industry is one of the greatest challenges that companies and projects are facing, because it has prevented companies from having an adequate growth. It is also pointed out that the lack of the application of risk management causes projects with delays, which end up with a high over cost and a worn relationship with customers; it calls the attention that these same results were observed a decade earlier by the publication Re-Thinking Construction [36].

Then, besides what is described, it is stated in this paper that another cause of this situation is the lack of measurement of what happened during the realization of the project at its end or after, to find out if the risk management was effective or not. Then it is proposed that a methodology should be designed to achieve this purpose and that, with the information provided by the methodology, it would be possible to find out how PRM works really and obtain lessons learned for future projects.

\section{Research Methodology}

Thus, this research aims to propose a preliminary model for measuring PRM' performance. In order to do this, it was necessary to identify the key factors and variables that explain risk management performance. To achieve this, the following stages were carried out:

1) Literature review: various databases, scientific articles, and books were consulted. An attempt was made to identify if there is any model proposed to measure PRM performance and what would be the relevance of being able to do it. This review allowed the identification of key PRM concepts, the establishment of the existing gaps, and the creation of a frame of reference.

2) Development of a preliminary proposal of the performance measurement model: in this stage, risk management experts/practitioners were interviewed, being all of them persons involved in the construction industry, the insurance industry, or the academic world. Interviews were semi-structured, and main topics addressed were risk and uncertainty, risk management and the process of risk management based on its actual application to construction projects. In the second stage, key variables were defined and the preliminary model for the measurement of risk management performance in construction projects was constructed based on the application of risk responses.

3) Validation of the model: once the previous stage was completed, risk management experts and practitioners validated the model, the key performance indicators and its application through an analysis and evaluation.

\section{Proposed model for project risk management performance measurement}

It was possible to observe in the literature that there are deficiencies in the application of risk management in construction projects. Therefore, a series of interviews were conducted with experts on the subject and, from this point of view, conclusions were drawn on the relevant issues for a proper management of risks and the know how about how the industry really conceives and applies risk management in construction projects. In order to carry out these interviews, experts in the field of construction who work both in the academic and professional fields were consulted. The consultation also included experts involved in the area of insurance, which is an important subject for the realization of the construction projects.

Then, first, this approach looked for ways to measure the performance of PRM at the end of any project. In this way, to know how effective the risk management implementation was based on four principal factors: 1) Risk Identification Performance; 2) Risk Analysis and Evaluation Performance; 3) Risk Responses Performance; and 4) Risk Management Profitability.

How would this measure work? The goal of this type of measurement is to know how the implementation of risk management performed during the execution of the project. Then it is necessary to evaluate this performance at the end of the project using the variables that indicated in figure 1. 


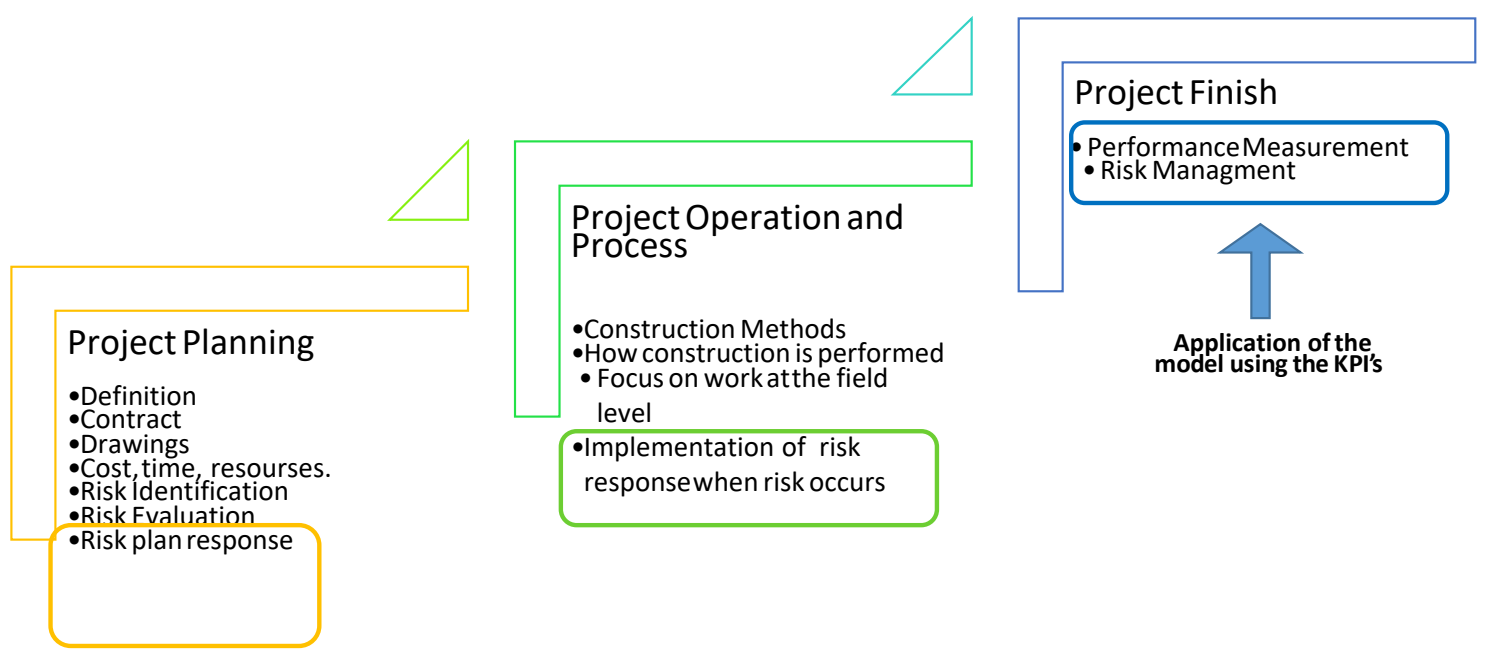

Fig. 1 Activities included in the PRM performance measurement.

As shown above, the key input variables for measuring PRM are the results of the following risk management activities: 1) Risk identification; 2) Risk evaluation; 3) Risk response plan; and 4) Implementation of risk responses when risks occurred. Then, at the finishing of the project, PRM performance is measured using the key performance indexes associated to a combination of these variables as shown in figure 2 and taking into account the four factors that were mentioned before.

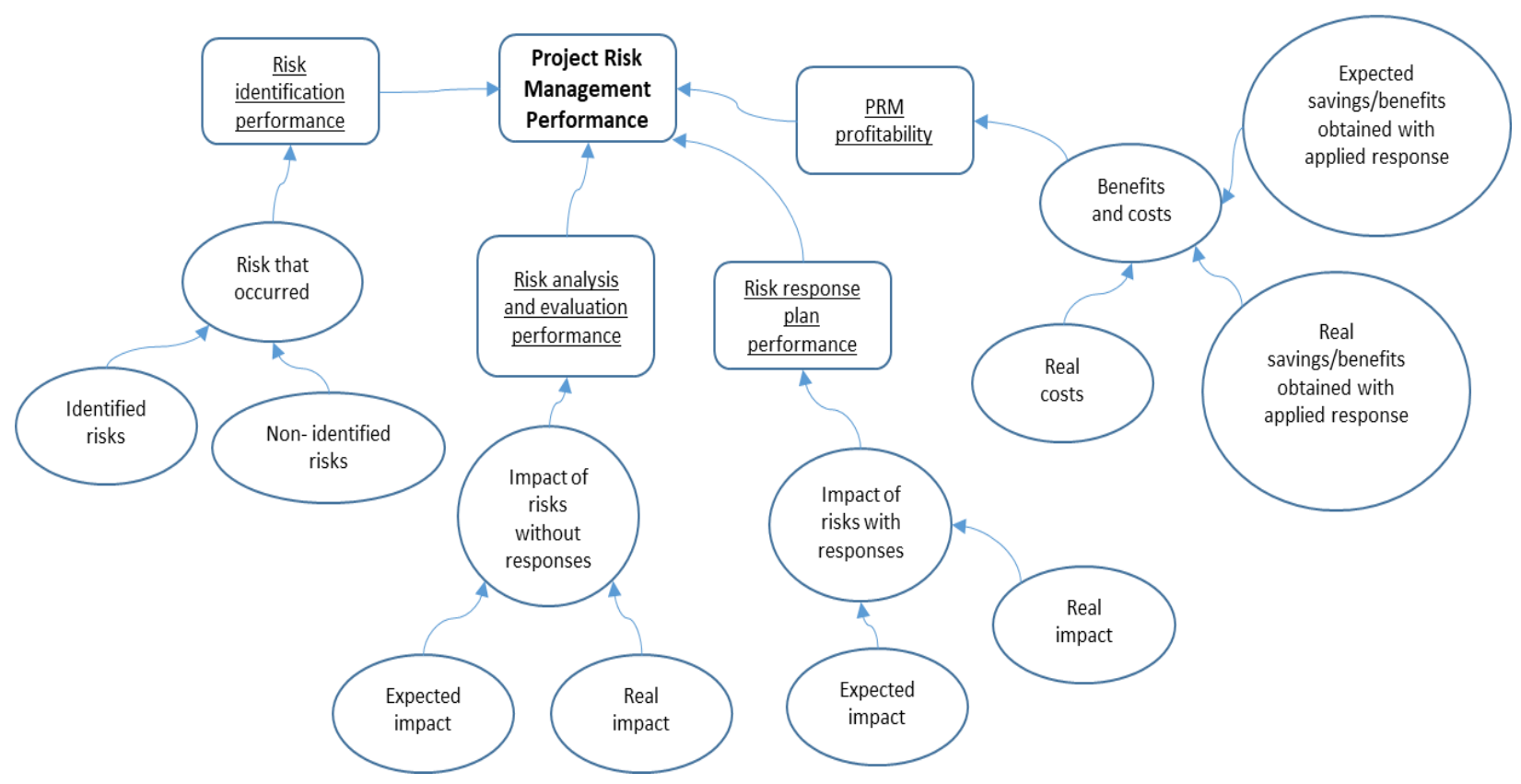

Fig. 2 Proposed model for measuring PRM performance. 


\section{Conclusions and Discussion}

This article has presented an effort made to address a topic that has not been investigated largely according to what the literature indicates. The research has sought to obtain a model that correctly reflects the factors that are involved in the performance of risk management in projects, in order to use these factors to measure this performance. The model presented is still in the process of evaluation and adjustment, in order to make a definitive and proven proposal in a longer time.

It is expected that the measurement of the performance of risk management in construction projects will provide construction companies with a valid and practical knowledge of the behavior of this important function and that will allow to have valuable lessons learned to produce a substantial improvement of this management. Likewise, it is expected that this information could demonstrate the value of risk management in an industry that does not apply it systematically, suffering the consequences of this failure. If the medium and long-term objective is to improve the performance of construction projects with better compliance with their objectives, then risk management could be a lever of great impact in this regard.

\section{References}

[1] Hillson, D. (2009). Managing risk in projects (Fundamentals of project management). Surrey, England: Grower Publishing Limited.

[2] Zhang, Y. (2016). Selecting risk response strategies considering project risk interdependence. International Journal of Project Management, 34(5), 819-830. http://doi.org/10.1016/j.ijproman.2016.03.001

[3] Howard, R., \& Serpell, A. (2012). Procurement management: analyzing key risk management factors. Rics Cobra 2012, (September), 11-13.

[4] Serpell, A., Ferrada, X., Howard, R., \& Rubio, L. (2014). Risk management in construction projects: a knowledge-based approach. In 27th IPMA (International Project Management Association), World Congress (pp. 1-5). Dubrovnik, Croatia.

[5] Wolbers, M. (2009). Application of risk management in Public Works organisations in Chile. Pontificia Universidad Católica de Chile/ University of Twente.

[6] Zou, P. X. W., Zhang, G., \& Wang, J. (2007). Understanding the key risks in construction projects in China. International Journal of Project Management, 25(6), 601-614. http://doi.org/10.1016/j.jproman.2007.03.001

[7] Baloi, D., \& Price, A. D. F. (2003). Modelling global risk factors affecting construction cost performance. International Journal of Project Management, 21(4), 261-269. http://doi.org/10.1016/S0263-7863(02)00017-0

[8] Marcelino-Sádaba, S., Pérez-Ezcurdia, A., Echeverría Lazcano, A. M., \& Villanueva, P. (2014). Project risk management methodology for small firms. International Journal of Project Management, 32(2), 327-340. http://doi.org/10.1016/j.ijproman.2013.05.009

[9] Melnyk, S. A., Bititci, U., Platts, K., Tobias, J., \& Andersen, B. (2014). Is performance measurement and management fit for the future? Management Accounting Research, 25(2), 173-186. http://doi.org/10.1016/j.mar.2013.07.007

[10] Franco-Santos, M., Lucianetti, L., \& Bourne, M. (2012). Contemporary performance measurement systems: A review of their consequences and a framework for research. Management Accounting Research, 23(2), 79-119. http://doi.org/10.1016/j.mar.2012.04.001

[11] Hubbard, D. W. (2010). How to Measure Anything, 304. Retrieved from http://book.douban.com/subject/5255145/

[12] Clive, K. (2014). How to Develop Meaningful Key Performance Indicators. Intrafocus.

[13] Taylor, A., \& Taylor, M. (2014). Factors influencing effective implementation of performance measurement systems in small and mediumsized enterprises and large firms: a perspective from Contingency Theory. International Journal of Production Research, 52(3), 847-866. http://doi.org/10.1080/00207543.2013.842023

[14] Zaleha, S., Rasid, A., Golshan, N. M., Khairuzzaman, W., \& Ismail, W. (2012). Risk Management, Performance measurement and Organizational performance: A Conceptual Framework. In 3rd International Conference on Business and Economic Research (pp. 1702-1715). Bandung, Indonesia.

[15] Corona-Suarez, G., AbouRizk, S. M., \& Karapetrovic, S. (2014). Simulation-Based Fuzzy Logic Approach to Assessing the Effect of Project Quality Management on Construction Performance. Journal of Quality and Reliability Engineering, 1-18. http://doi.org/10.1155/2014/203427

[16] Hubbard, D. W. (2009). The Failure of Risk Management (1st.). Hobroken, New Jersey: John Wiley and Sons Inc. Retrieved from http://scholar.google.com/scholar?hl=en\&btnG=Search\&q=intitle:No+Title\#0

[17] Mikes, A., \& Kaplan, R. (2013). Towards a Contingency Theory of Enterprise Risk Management (No. 13-063). Harvard Business School. Retrieved from http://www.hec.unil.ch/documents/seminars/dcc/1102.pdf

[18] Lee, E., Park, Y., \& Shin, J. G. (2009). Large engineering project risk management using a Bayesian belief network. Expert Systems with Applications, 36(3), 5880-5887. http://doi.org/10.1016/j.eswa.2008.07.057

[19] Tohidi, H. (2011). The role of risk management in IT systems of organizations. Procedia Computer Science, 3, $881-887$. http://doi.org/10.1016/j.procs.2010.12.144

[20] Aven, T. (2010). On how to define, understand and describe risk. Reliability Engineering \& System Safety, 95(6), 623-631. http://doi.org/10.1016/j.ress.2010.01.011

[21] Hillson, D. (2007). Understanding The Risk Management Universe - Consensus and Controversy. In The Risk Management Universe: A Guided Tour (2nd., p. 424). London: BSI Standars.

[22] Ward, S., \& Chapman, C. (2003). Transforming project risk management into project uncertainty management. International Journal of Project Management, 21(2), 97-105. http://doi.org/10.1016/S0263-7863(01)00080-1

[23] Banaitiené, N., Banaitis, A., \& Norkus, A. (2011). Risk management in projects: peculiarities of Lithuanian construction companies. International Journal of Strategic Property Management, 15(1), 60-73. http://doi.org/10.3846/1648715X.2011.568675 
[24] Carter, A., \& Chinyio, E. (2010). Effectiveness of risk management: Barriers and solutions. In PM-05 Advancing Project Management for the 21st Century: Concepts, Tools \& Techniques for Managing Succesful Projects (pp. 135-143). Crete, Greece.

[25] Dikmen, I., Birgonul, M. T., Anac, C., Tah, J. H. M., \& Aouad, G. (2008). Learning from risks: A tool for post-project risk assessment. Automation in Construction, 18(1), 42-50. http://doi.org/10.1016/j.autcon.2008.04.008

[26] ISO. (2009). ISO 31000 (Vol. 2009).

[28] NASA. (2011). NASA Risk Management Handbook. Washington, D.C.

[29] Osipova, E., \& Eriksson, P. E. (2013). Balancing control and flexibility in joint risk management: Lessons learned from two construction projects. International Journal of Project Management, 31(3), 391-399. http://doi.org/10.1016/j.ijproman.2012.09.007

[30] Papadaki, M., Gale, A. ., Rimmer, J., \& Kirkham, R. . (2010). Factors Influencing Project Risk Management Decision Making. In PM-05 Advancing Project Management for the 21st Century: Concepts, Tools \& Techniques for Managing Succesful Projects (pp. 536-544). Heraklion, Crete, Greece.

[31] Raz, T., \& Michael, E. (2001). Use and benefits of tools for project risk management. International Journal of Project Management, 19(1), 917. http://doi.org/10.1016/S0263-7863(99)00036-8

[32] Ren, Y., Yeo, K. T., \& Ren, Y. (2014). Risk Management Capability Maturity and Performance of Complex Product and System ( CoPS ) Projects with an Asian Perspective. Journal of Engineering, Project and Production Management, 4(2), 81-98.

[33] Standars Australia. (2007). AS/NZS 4360:2004 Risk Management. New Zeland: Standars Australia.

[34] Washington State Departement of Transportation. (2014). Project Risk Management Guide. Washington State Department of Transportation.

[35] Khameneh, A.-H., Taheri, A., \& Ershadi, M. (2016). Offering a framework for evaluating the performance of project risk management system. Procedia -Social and Behavioral Sciences, 226(226), 82-90. http://doi.org/10.1016/j.sbspro.2016.06.165

[36] Dallas, M. . (2008). Value \& Risk Management (A guide to best practice). Oxford, UK: Blackwell Publishing Ltd. 